\title{
A Multimodal Particle Swarm Optimization-based Approach for Image Segmentation
}

\author{
Taymaz Rahkar Farshi ${ }^{1, *}$, John H. Drake², Ender Özcan ${ }^{3}$ \\ ${ }^{1}$ Department of Software Engineering, Altınbaş University, Istanbul. 34217, Turkey \\ ${ }^{2}$ School of Informatics, University of Leicester, University Road, Leicester, LE1 7RH, UK \\ ${ }^{3}$ School of Computer Science, University of Nottingham, Nottingham, NG8 1BB, UK
}

\begin{abstract}
Color image segmentation is a fundamental challenge in the field of image analysis and pattern recognition. In this paper, a novel automated pixel clustering and color image segmentation algorithm is presented. The proposed method operates in three successive stages. In the first stage, a three-dimensional histogram of pixel colors based on the RGB model is smoothened using a Gaussian filter. This process helps to eliminate unreliable and non-dominating peaks that are too close to one another in the histogram. In the next stage, the peaks representing different clusters in the histogram are identified using a multimodal particle swarm optimization algorithm. Finally, pixels are assigned to the most appropriate cluster based on Euclidean distance. Determining the number of clusters to be used is often a manual process left for a user and represents a challenge for various segmentation algorithms. The proposed method is designed to determine an appropriate number of clusters, in addition to the actual peaks, automatically. Experiments confirm that the proposed approach yields desirable results, demonstrating that it can find an appropriate set of clusters for a set of well-known benchmark images.
\end{abstract}

Keywords: Color image segmentation, Clustering, Particle Swarm Optimisation, Multimodal optimisation

\section{Introduction}

Image segmentation is the first step in image analysis and refers to the grouping of pixels in an image into several meaningful homogeneous regions (Kurugollu, Sankur, \& Harmanci, 2001). There are a wide range of existing methods for image segmentation, which can be categorized into threshold-based, clustering-based, region-based, edge-based, and physics-based segmentation methodologies. Additionally, there are other hybrid image segmentation techniques that use a combination of multiple approaches (Hettiarachchi \& Peters, 2017). Approaches to segmentation can be further decomposed into bi-level segmentation methods, which split images into two segments, and multi-level segmentation methods which split images into multiple segments (Pare, Kumar, Bajaj, \& Singh, 2016; Sarkar \& Das, 2013). Although some segmentation algorithms, such as thresholding methods (e.g., (Otsu, 1979; Kapur, Sahoo, \& Wong, 1985)), are developed for bi-level segmentation, they can also be extended to deal with multi-level segmentation (Aziz, Ewees, \& Hassanien, 2017; Horng \& Liou, 2011; Khairuzzaman \& Chaudhury, 2017; Raja, Rajinikanth, \& Latha, 2014; V Rajinikanth, Aashiha, \& Atchaya, 2014; Sathya \& Kayalvizhi, 2011). Multi-level segmentation is generally a more complex and computationally expensive problem than bi-level segmentation. Upon increasing the desired number of segments, the computational complexity of the problem increases exponentially, 
making the use of exact methods to exhaustively search all possible solutions impractical. As a result, heuristic algorithms are often preferred, and have proven successful in solving such problems in the literature previously.

The segmentation of color images (RGB) is extremely challenging, due to the variety of possible color intensities and the presence of three color channels, unlike gray images which have only a single color channel (Kumar, Pant, Kumar, $\&$ Dutt, 2015). According to Cheng et al. (2001), the segmentation of color images has attracted increasing research attention due to the larger quantity of information contained within color images, and the computational power required to handle the processing of such images is now less expensive than it was previously.

The $k$-means and $c$-means algorithms are two of the most well-known clustering approaches used in color image segmentation, often providing very good results. However, one of the limitations is that the number of clusters is a parameter that must be defined a priori, and deciding this value is not trivial. Computational time is also a major concern while solving the problem, as it is dependent on the number of clusters required, as well as the size of the image. Threshold-based methods using histograms are commonly adopted in image segmentation. Unlike regionbased methods which require a high volume of computation to calculate spatial pixel similarity, threshold-based approaches use information contained in histograms. Threshold-based techniques are also considered to be relatively quick, since they generally only need to process the pixels in an image once (Shapiro \& Stockman 2001), however most are applied to gray-level images using one-dimensional histograms. Historically, few studies applying such methods to color images have appeared in the literature, due to the higher dimensionality involved, and the complexity associated with each color component in each dimension being independent. However, in recent years there has been increased research attention given to color image segmentation based on two- and three-dimensional histograms. The main difficulty faced by existing approaches is determining the number of segments to split an image into, a userdefined parameter (Yang \& Huang, 2012).

Due to the nature of the three-dimensional data structures used to represent color images as RGB values, the analysis of color images for global threshold selection to be used in segmentation is a demanding task. There are studies in the literature presenting transformation techniques that map the representation of an image into one or two dimensions, before performing segmentation, i.e., (Tenenbaum, Garvey, Weyl, \& Wolf, 1974; Underwood \& Aggarwal, 1977). Among others, Sarabi \& Aggarwal (1981) and Schacter, Davis, \& Rosenfeld (1976) convert the three-dimensional histogram into a binary tree form, where each node is an indicator of a band in the RGB range. As a result, the performance of these algorithms is sensitive to the number of RGB points which quantify the nodal values in the transformed binary tree structure.

Kurugollu et al. (2001) proposed a color image segmentation algorithm that contained two main steps: multithresholding and fusion. Firstly, two-dimensional histograms are formed by combining pair-wise color bands (RG, $\mathrm{GB}$, and $\mathrm{BR})$. The histogram of each band-pair was used to find existing peaks that corresponded to cluster centers. Based on the peaks obtained, the fusion phase aligns the cluster labels in each histogram before applying a spatialchromatic majority filter to combine the two-dimensional histograms into a final segmentation map. Tan and Isa (2011) introduced a hybrid method based on histogram thresholding and fuzzy $c$-means (FCM). This method used histogram thresholding to attempt to overcome the issue that fuzzy c-means is sensitive to the number of clusters and 
initial assignment of cluster centroids. Their histogram thresholding technique was used to obtain all possible uniform regions of color images, before the FCM algorithm was used to improve the compactness of the regions formed by the clusters.

Panagiotakis et. al. (2011) proposed an image segmentation method using a growing-merging in spatial domain based on tree equipartition and Bayesian flooding processes for feature extraction. Rajinikanth and Couceiro (2015) introduced an approach for color image segmentation based on RGB histograms. The "firefly" optimization algorithm and modified variants were applied to optimize Otsu's between-class variance function for each color component. The RGB histogram of an image was taken into account for bi-level and multi-level segmentation. Lifang and Songwei (2017) introduced a color image segmentation method using a modified firefly algorithm to optimize multi-level Kapur's entropy, minimum cross entropy and between-class variance objective functions. All three functions were applied to all three color components. Syu et. al. (2017) proposed a method which was built on hierarchical image segmentation based on iterative contraction and merging. In their work, finding the optimum number of similar region pairs among neighbouring regions was considered as an optimization problem. Deep Learning was used for semantic image segmentation by Chen et. al. (2018).

As discussed above, the choice of the number of segments to split an image into is critical to the performance of an image segmentation method, and usually requires human expert input. In this paper, we will introduce a novel image segmentation approach that aims to automatically determine both the number of clusters that exist within that image and the pixels that are contained within each cluster. The center of each cluster can be determined by finding the peaks within a three-dimensional histogram of a color image, derived using the RGB values of the pixels in the image and smoothened via the application of a Gaussian filter. Here we use a multimodal variant of particle swarm optimization (PSO) with a local search strategy, to locate all of the global and local peaks within a histogram, and hence determine the centre points for each cluster. The number of peaks discovered by PSO provides the number of clusters contained within the image automatically. Based on the peaks discovered, individual pixels are then assigned to the closest cluster by Euclidean distance, providing the final segmented image.

The paper is structured as follows. Section 2 presents the concepts of multimodal optimization and discovery of peaks in a given RGB histogram. Section 3 provides a description of the proposed method. Section 4 analyzes and compares the results obtained for the proposed approach and c-means to a set of well-known benchmark problems. Finally, some concluding remarks are given in Section 5.

\section{Multimodal optimization and Particle Swarm Optimisation}

Unimodal optimization approaches usually search for a single global optimum when solving a given problem. On the other hand, multimodal optimization approaches explore the search space with the goal of detecting global and local optima simultaneously. Multimodal optimization algorithms are attractive in many real-world problems, particularly where multiple solutions of differing quality are required by the end users. Particle Swarm Optimization (PSO) is a well-known optimization algorithm introduced by Eberhart and Kennedy (1995). Although this algorithm was initially proposed as a unimodal approach, it has been extended to multimodal form a number of times in the literature, 
exploiting the mechanisms for particles' motion to detect both global and local optima (Parsopoulos and Vrahatis, 2001; Brits et al., 2007).

In traditional PSO, each particle uses two vectors: position $(\boldsymbol{x})$ and velocity $(\boldsymbol{v})$. The position vector encodes the location of a particle and the velocity vector shows the amount of change in position and direction of a particle. PSO is an iterative algorithm. The search process starts by assigning random values (locations) to each particle in the solution space. The position components are then updated based on the particles' velocity components at each iteration $i$. From each individual particle's experience previously gained during the search process, the swarm's overall experience and an element of stochasticity, the new velocity vector of a particle can be calculated by Equation (1).

$$
\begin{aligned}
& v_{i}(t+1)=w \times v_{i}(t)+R_{1} \times C_{1}\left(\mathrm{p}_{i}^{\text {best }}-x_{i}\right)+R_{2} \times C_{2}\left(g^{\text {best }}-x_{i}\right) \\
& x_{i}(t+1)=x_{i}(t)+v_{i}(t+1)
\end{aligned}
$$

where $v_{i}(t)$ and $x_{i}(t)$ represent the velocity and position of the $i^{\text {th }}$ particle at iteration $\mathrm{t}, \mathrm{w}$ is the inertia weight, $p_{i}^{\text {best }}$ and $g^{\text {best }}$ represent the position of the best solution found so far by the $i^{\text {th }}$ particle and its neighbors, respectively. $R_{1}$ and $R_{2}$ are two randomly generated numbers uniformly distributed in the range [0,1]. $C_{1}$ and $C_{2}$ are the confidence of a given particle in itself and its neighbors respectively. The mechanism for particle motion in traditional PSO can easily be extended to deal with multimodal problems. In the unimodal form of PSO, all particles in the population converge towards the same point (gbest) in the search space. However, unlike the unimodal form, multimodal PSO seeks multiple gbests across the search space (Wang, Moon, Yang, \& Wang, 2012).

Inspired by electrostatic interactions between particles, Barrera and Coello Coello (2009) presented a modified PSO variant to tackle multimodal problems. To reach multiple optima, individual particles move from their current position towards the particle with greatest electrostatic conduction calculated based on current fitness value. These interactions are mathematically calculated per $F_{i, j}=Q_{i} Q_{j} /\left(4 \pi r^{2} \varepsilon_{0}\right)$, where $Q_{i, j}, r \neq 0$, and $\varepsilon_{0}$ are the electrical charges of the interacting particles, the distance between them, and the vacuum permittivity respectively. To put these concepts in the context of an optimization framework, the electric charge of the particles represents the value of the fitness function, which is weighted by the Euclidean distance, i.e., $F_{i, j}=\alpha f\left(p_{i}\right) f\left(p_{j}\right) /\left\|p_{i}-p_{j}\right\|^{2}$. Here $4 \pi \varepsilon_{0}$ as constant scalar is replaced by $\alpha$ which is calculated following $\mathrm{Li}$ (2007). For a constant index $j$,

$$
\begin{aligned}
& \text { index }_{i}=\underset{\mathrm{j}=1: \mathrm{M}}{\arg \max } F_{i, j} \text { is used to replace the value of gbest in Eq. (1) } \\
& v_{t}=w \cdot v_{t-1}+R_{1} \times C_{1}\left(p_{i}^{\text {best }}-x_{i}\right)+R_{2} \times C_{2}\left(p_{\text {index }}-x_{i}\right) \\
& x_{i}=x_{i}+v_{i}
\end{aligned}
$$


This modified variant of PSO for multimodal problems is used in the experimentation performed within this paper.

\section{Proposed Segmentation Method (3DHP)}

In this section we will describe our proposed approach, referred to as 3DHP herein. As discussed in the introduction, due to the difficulty in processing three-dimensional histograms, many segmentation methods based on histograms only deal with one-dimensional gray images. For color images using the RGB model, the color of a pixel is a combination of the three independent color channels red, green and blue. Each pixel can be represented by a threedimensional feature vector that contains three colors of an image pixel. Accordingly, a histogram based on these three color components can be formed (Navon, Miller, \& Averbuch, 2005).

The existence of peaks in a histogram indicates that there are different segments in the image, with each peak representing a different segment. Because of the nature of the data, the histograms obtained are usually very noisy (Kurugollu, et al., 2001). Consequently, three-dimensional histograms are often smoothed by a three-dimensional Gaussian filter to reduce the effect of this noise. This procedure also removes small non-significant local peaks from the histogram. The three-dimensional histogram, original color distribution and color distribution after the smoothening process for the Lenna image are illustrated in Figure 1.

Next, we use the multimodal variant of PSO introduced by Barrera and Coello Coello (2009) and discussed in Section 2 above to locate all of the peaks within the image, using the smoothed histogram. It is well-known that the fine search aspect of multimodal algorithms is a challenging task, as the algorithm may converge close to the global/local optima without reaching the desired goal. Qu et al. (2012) proposed an additional step to several existing multimodal PSO algorithms, aimed at enhancing the effectiveness of local search, which increases the likelihood of finding optima as well as reducing the number of function evaluations required for convergence.

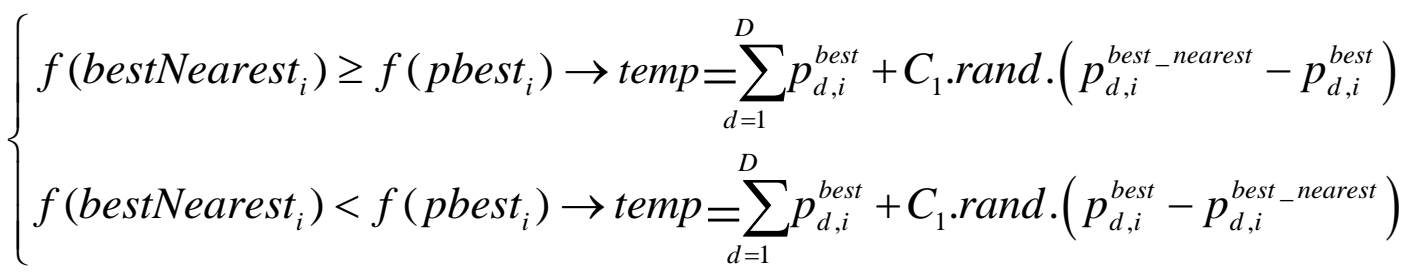

$$
\begin{aligned}
& f(\text { temp })>f\left(\text { pbest }_{i}\right) \rightarrow \text { pbest }_{i}=\text { temp }
\end{aligned}
$$

In the proposed method, we employ this additional local search step, in order to increase the performance level of our approach. After locating the best $K$ dominant peaks, $K$ sets of peak intensity level in each RGB component are automatically obtained. Then $\quad P_{1}^{r g b}=\left(r_{1}, g_{1}, b_{1}\right), \quad P_{2}^{r g b}=\left(r_{2}, g_{2}, b_{2}\right), \quad P_{3}^{r g b}=\left(r_{3}, g_{3}, b_{3}\right)$ $\cdots P_{K}^{r g b}=\left(r_{K}, g_{K}, b_{K}\right)$ are the sets of peaks that are considered as cluster centers. In addition, in order to eliminate 
non-dominant clusters, it is advantageous to limit the distance between two peaks. Based on a given distance limit parameter, dominating peaks eliminate non-dominating peaks within that radius. It is important to note that this procedure is optional and could be omitted. In our experiments, this parameter is set to 80 pixels. The number of peaks discovered represents the number of clusters and each peak is considered as the cluster head.

Eventually, each pixel is assigned to the closest peak in terms of Euclidean distance. The Euclidean distance between $\mathrm{k}_{\text {th }}$ peak and $(\mathrm{i}, \mathrm{j})_{\text {th }}$ pixel is calculated as follows:

$$
\left\|P_{k}^{r g b}-I_{i, j}^{r g b}\right\|=\sqrt{\left(P_{k}^{r}-I_{i, j}^{r}\right)^{2}+\left(P_{k}^{g}-I_{i, j}^{g}\right)^{2}+\left(P_{k}^{b}-I_{i, j}^{b}\right)^{2}}
$$

The proposed algorithm is summarized by the following three steps:

- Compute (Figure 1(c)) and smoothen (Figure 1(d)) the three-dimensional histogram

- Apply multimodal PSO to find the dominant peaks within the histogram, representing the clusters within the image

- Assign each pixel to the closest peak (cluster) in order to segment the image

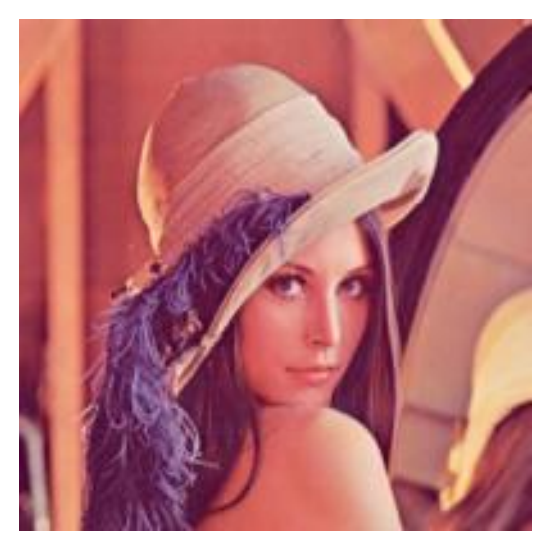

(a)

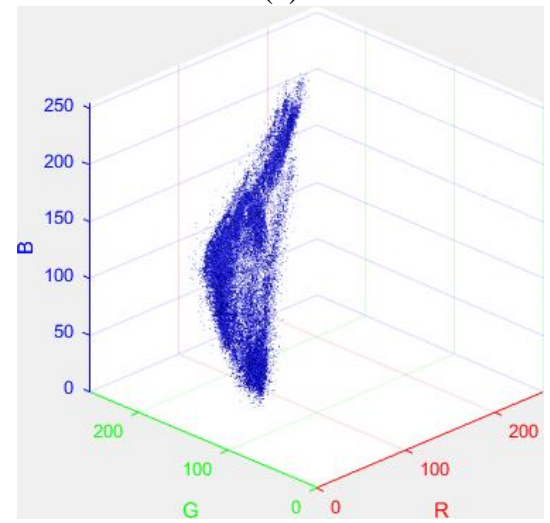

(c)

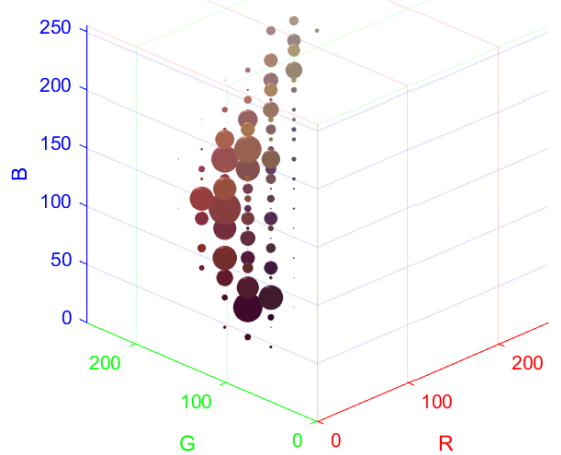

(b)

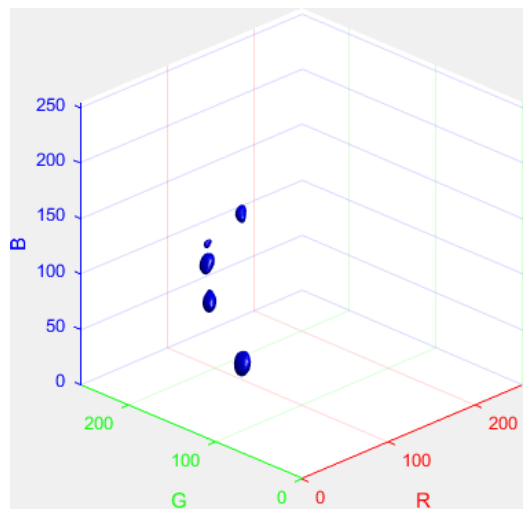

(d)

Figure 1. Illustration of three-dimensional histogram, color distribution and smoothed color distribution of Lenna. (a) original Lenna image, (b) three-dimensional histogram of Lenna, (c) and (d) show the normal and smoothened RGB representation of Lenna. 


\section{Experimental results and performance evaluation}

Our experiments were implemented using Matlab R2014 on a Core i7-3632qm 2.20GHz CPU, 8 GB RAM running Windows 10. The proposed approach has been tested over the well-known Lenna image and the standard publicly accessible Berkeley segmentation dataset (Martin, Fowlkes, Tal, \& Malik, 2001). In this paper, 20 images from this dataset have been selected to demonstrate the capability of the proposed method. The size and variance of the Gaussian filter used to smoothen the are empirically set to 11 and 7. The segmentation results of the proposed scheme depend on the quality of the clusters. In order to evaluate the quality of the proposed method, we compare to the fuzzy $c$ means (FCM) (Sutton, Bezdek, \& Cahoon, 2000) and recently proposed SFFCM (Lei, et al., 2018) methods from the literature, using six quantitative performance assessment metrics and computation time (T).

As the test images are somewhat heterogeneous, visual judgment is difficult and may not be sufficient for analysis

purposes. Therefore quantitative evaluation criteria is required to measure the performance of segmentation (Chang, Zhao, Liu, \& Zheng, 2016). Dividing one region of the reference image into two or more regions (over-segmentation), and conversely, representing two or more regions of the reference image by a single region (under-segmentation) are both undesirable. It is obvious that by increasing the number of segments, the homogeneity of pixels in each segment will also increase. On the other hand, a segmented image formed by a large number of small segments may not be satisfactory. Hence the number of segments and their homogeneity plays an important role in a successful segmentation (Hettiarachchi \& Peters, 2017).

There are multiple quantitative assessment functions that can be used to evaluate the image segmentation results. Three of the most fundamental functions used for numerical evaluation of image segmentation results are as follows: $F(I)$ proposed by Liu and Yang (1994) which penalizes over-segmentation:

$F=\frac{1}{1000(M \times N)} \sqrt{R} \sum_{i=1}^{R} \frac{e_{i}^{2}}{\sqrt{A_{i}}}$

F'(I) proposed by Borsotti et al. (1998) which is robust for noisy images:

$$
F^{\prime}(I)=\frac{1}{10000(N \times M)} \sqrt{\sum_{A=1}^{\operatorname{Max}}[R(A)]^{1+\frac{1}{A}}} \times \sum_{i=1}^{R} \frac{e_{i}^{2}}{\sqrt{A_{i}}}
$$

and Q(I) further refined from $\mathrm{F}(\mathrm{I})$ by Borsotti et al. (1998), which penalizes non-homogeneous regions:

$$
Q(I)=\frac{1}{10000(M \times N)} \sqrt{R} \sum_{i=1}^{R}\left[\frac{e_{i}^{2}}{1+\log A_{i}}+\left(\frac{R\left(A_{i}\right)}{A_{i}}\right)^{2}\right]
$$


For the three formulae above, $I$ is image, $M \times N$ is the image size (number of pixels), $\mathrm{R}$ is the number of regions identified, $A_{i}$ is the number of pixels present in the $i^{\text {th }}$ region. $e_{i}$ represents the color error in region $i$, which is defined as the sum of the Euclidean distances between (RGB) pixels of region $i$ in the original color image and the attributed (RGB) pixel values in region $i$ in the archived segmented image. $\sqrt{R}$ is a penalizing term that discourages oversegmentation (non-homogeneous regions). A small value of $\mathrm{F}$ and $F(I)$ is desirable. $R(A)$ represents the number of regions that have an area of exactly $A$, and Max represents the largest region in the segmented image.

Moreover, three other common evaluation criteria are used for quantitative comparison. The Probabilistic Rand Index (PRI) (Martin, et al., 2001) counts the pairs of pixels that not only have consistent labels in the segmented image, but also have consistent labels in the ground truth image. Variation of Information (VoI) or shared information distance (Meila, 2002) measure the correctness of segmentation by calculating the distance between two segmentations. The Global Consistency Error (GCE) (Martin, et al., 2001) evaluates the extent to which one segmentation can be a refinement of another. In this way, the associated segmentations are consistent because they represent the same image segmented at different scales.

The visual qualitative analysis of all images is shown in Figure 2 and Figure 3. In Figure 3, the segmentation results for each method are shown using the mean average color value for all pixels in that cluster, and also using a distinct color set to the original image to clearly show the clusters found. The three-dimensional histogram peak locations and cluster centroids for each cluster identified by 3DHP, FCM and SFFCM are provided in Table 1. Likewise, Table 2 and Table 3 indicate the numerical qualitative analysis of the results obtained using each of the three methods tested. If the ideal number of clusters was known in advance, FCM could yield robust segmentation results. In our experiments, the number of clusters for FCM is determined based on the number of peaks identified by 3DHP.

It is clear from Figure 2 and Figure 3 that the proposed scheme is capable to achieve viable segmentation with wellpreserved edges. Table 2 shows that for all of the test images, 3DHP, FCM and SFFCM all produce favorable and reliable results. The main difference is that 3 DHP does not require the number of segments to be determined in advance. Table 2 demonstrates that the actual computation time of the proposed technique is significantly lower than FCM. The computational complexity of FCM and SFFCM increases exponentially as the image size and number of clusters increases, whereas the computational effort required to execute 3DHP is independent of the size of the image. 


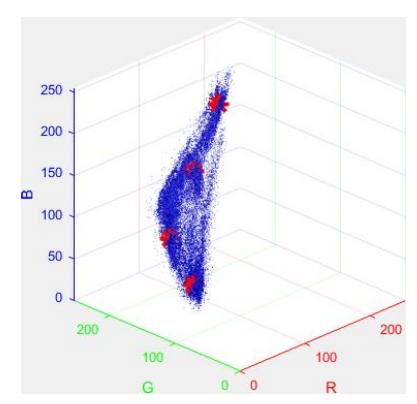

(a)

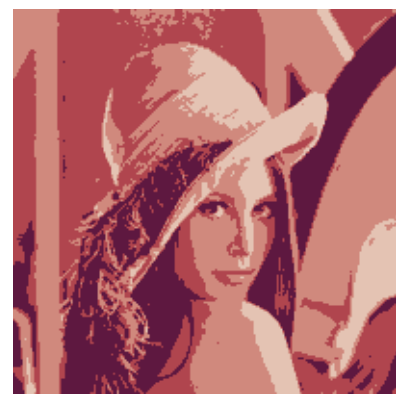

(b)

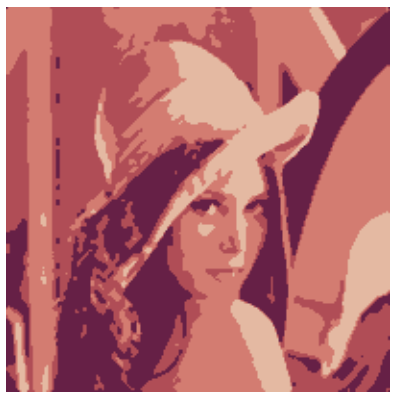

(c)

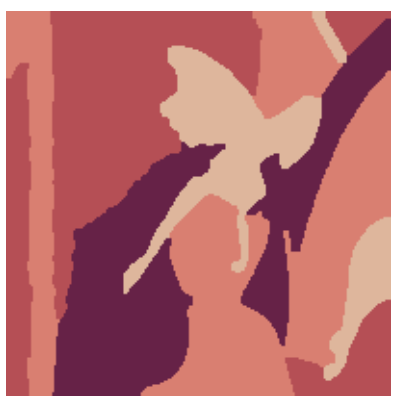

(d)

Figure 2. (a) RGB distribution and peak locations (b) segmented image by 3DHP, $\mathrm{m}=4$, (c) segmented image by FCM, $m=4$, (d) segmented image by SFFCM, $m=4$

Figure 2(a) shows the cluster centroids located in the Lenna image by 3DHP while Figure 2(b), Figure 2(c) and Figure 2(d) show the segmented image obtained by 3DHP, FCM and SFFCM, respectively. By observing the results shown in Figure 3 for ' 135069 ' and ' 238011 ', it seems that 3DHP is more effective at segmenting large homogenous regions, such as the background region in these two images. For ' 135069 ', the sky is divided into multiple segments using FCM and SFFCM, whereas with 3DHP, except for the top-left corner, the sky is well distinguished. For the '238011' image, the moon in the sky disappears entirely when using FCM and SFFCM. For the '232038' image, 3DHP and FCM show better segmentation results than SFFCM as in the case of SFFCM, pixels representing the subject's eyes are mistakenly assigned to the face. For the ' 124084 ' image, with SFFCM all pieces of the flower and background are clearly distinguished, however this is not the case with two other algorithms. Additionally, for image ' 71046 ', using 3DHP the sky is segmented correctly, whereas FCM over-segments the sky, dividing it into two separate regions. 


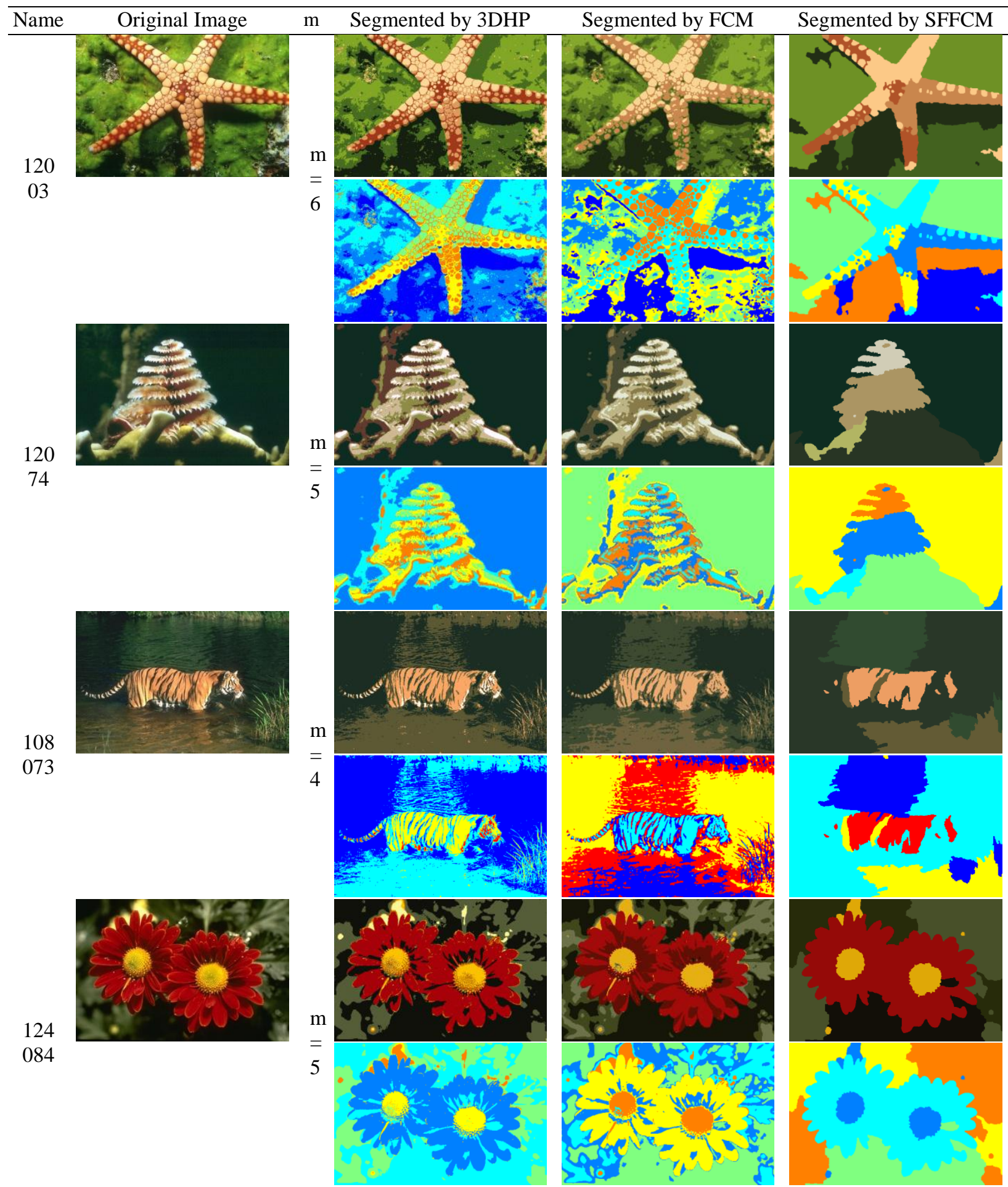

Figure 3. Original benchmark image and segmented results 


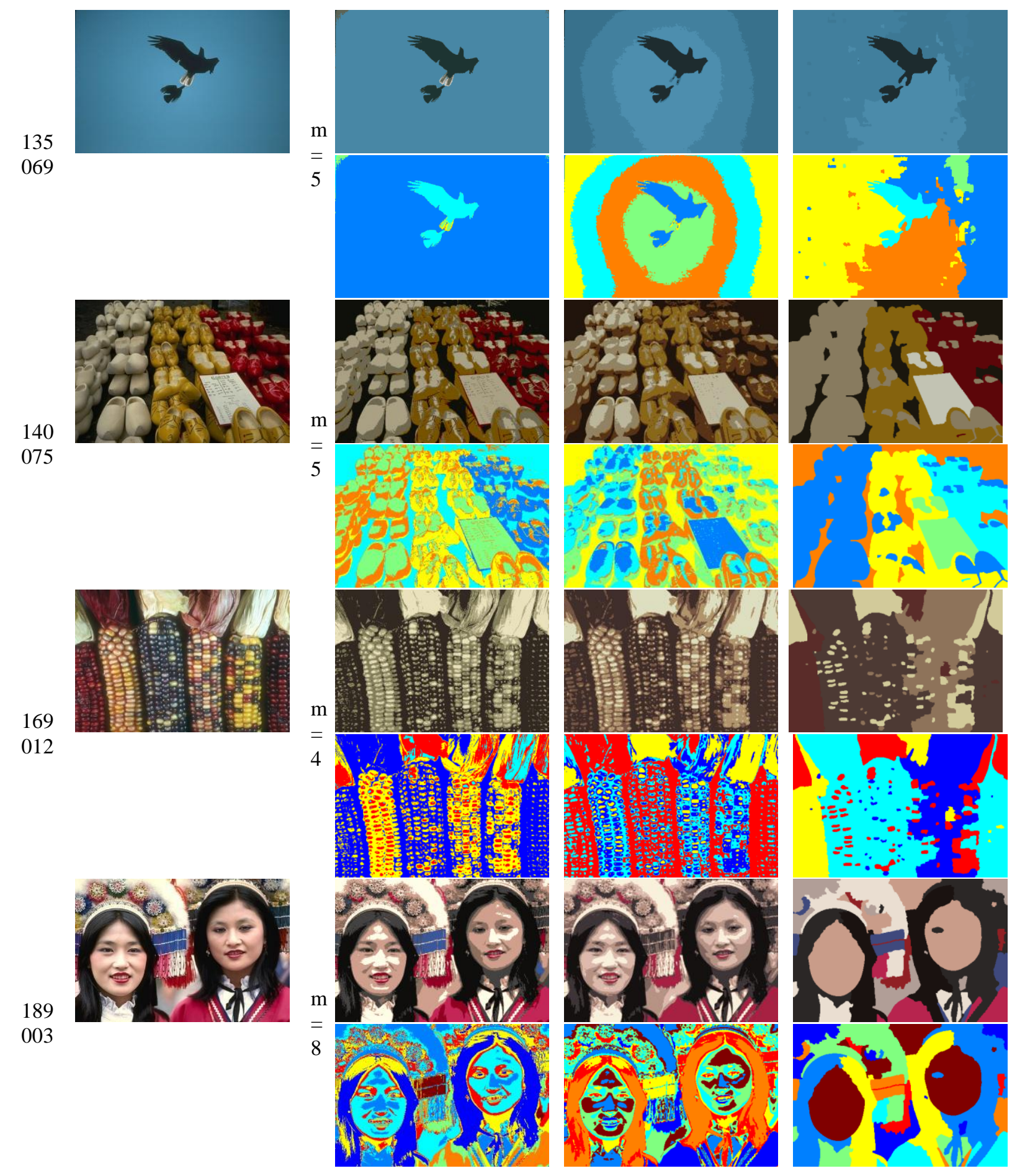

Figure 3. Continued 


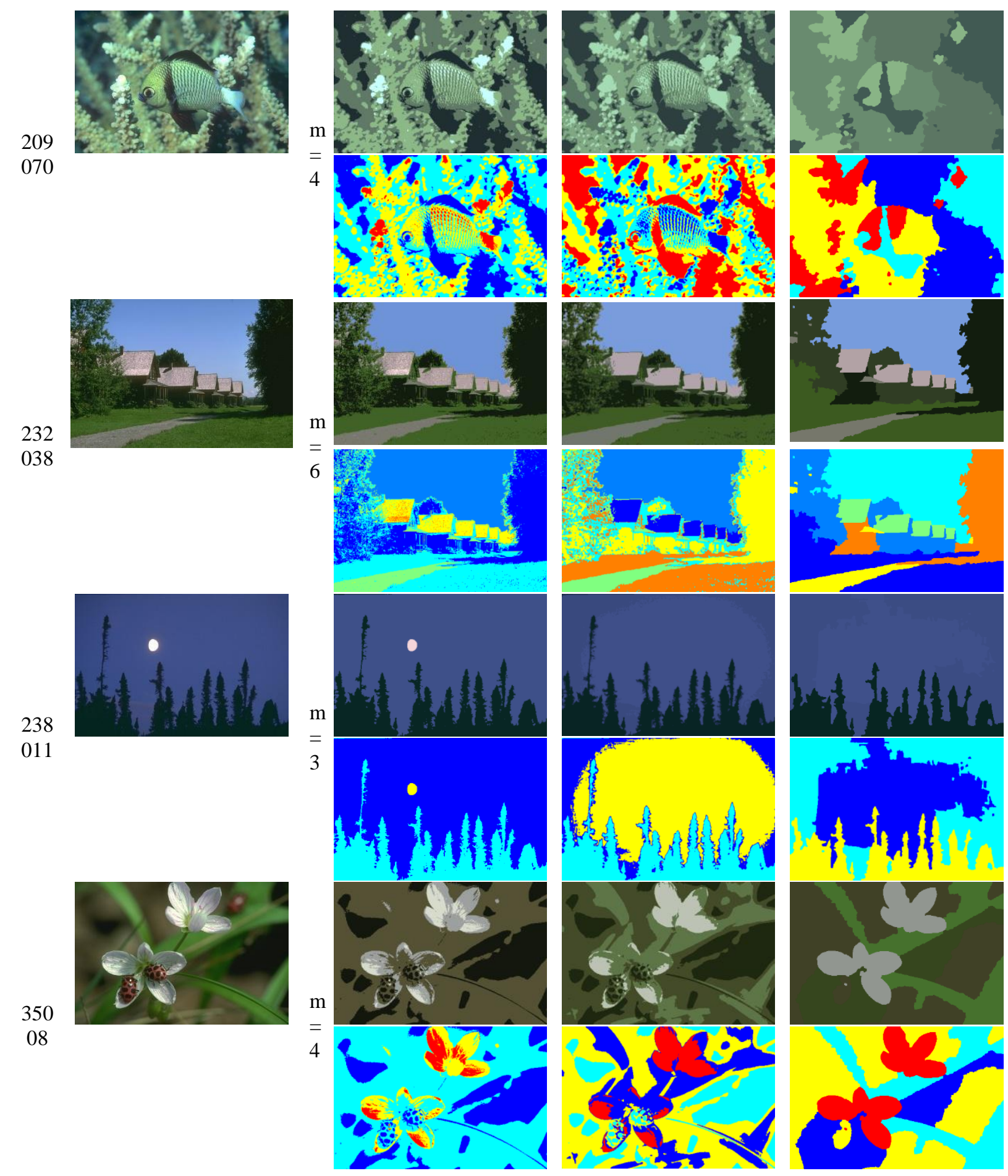

Figure 3. Continued 


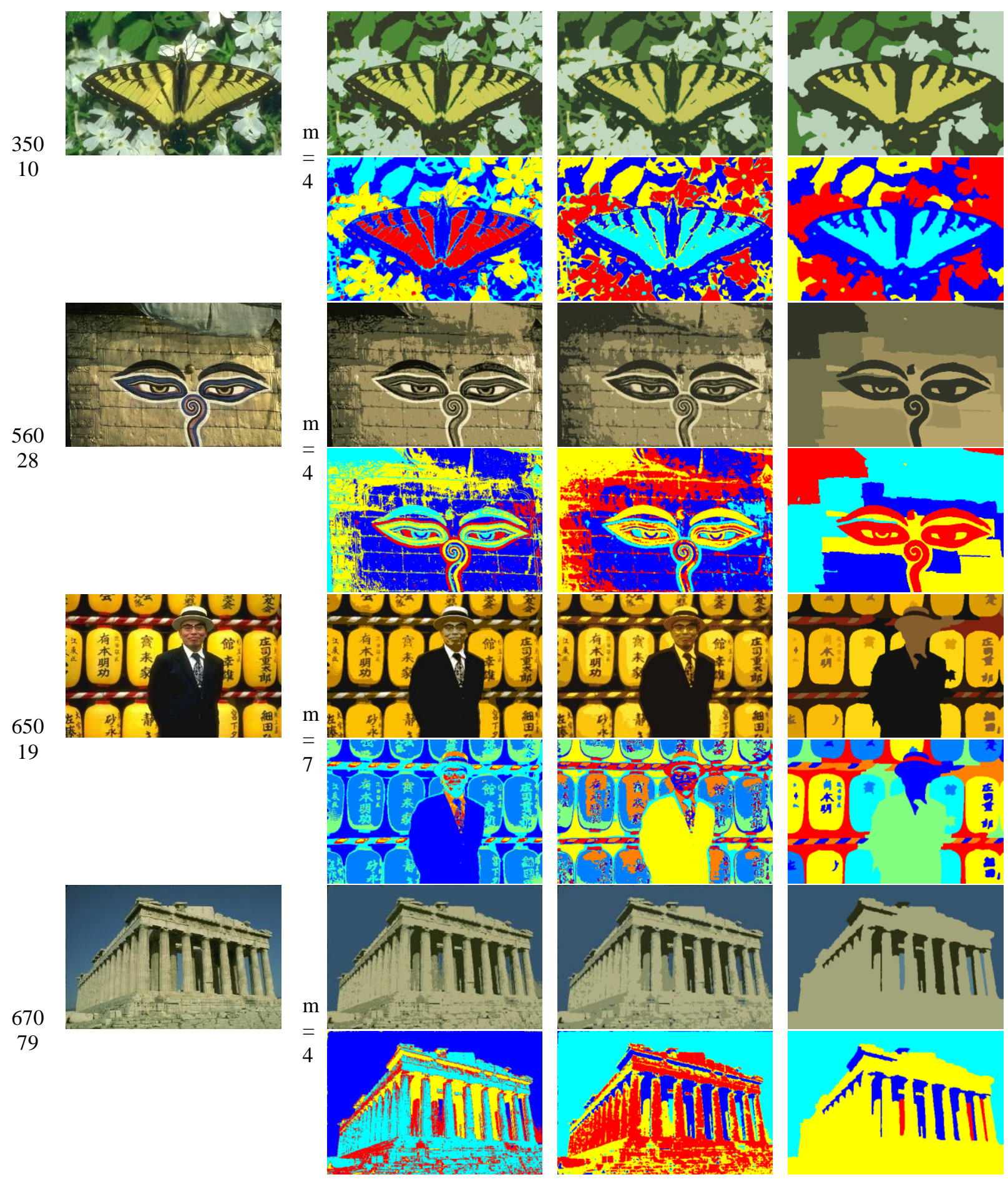

Figure 3. Continued 


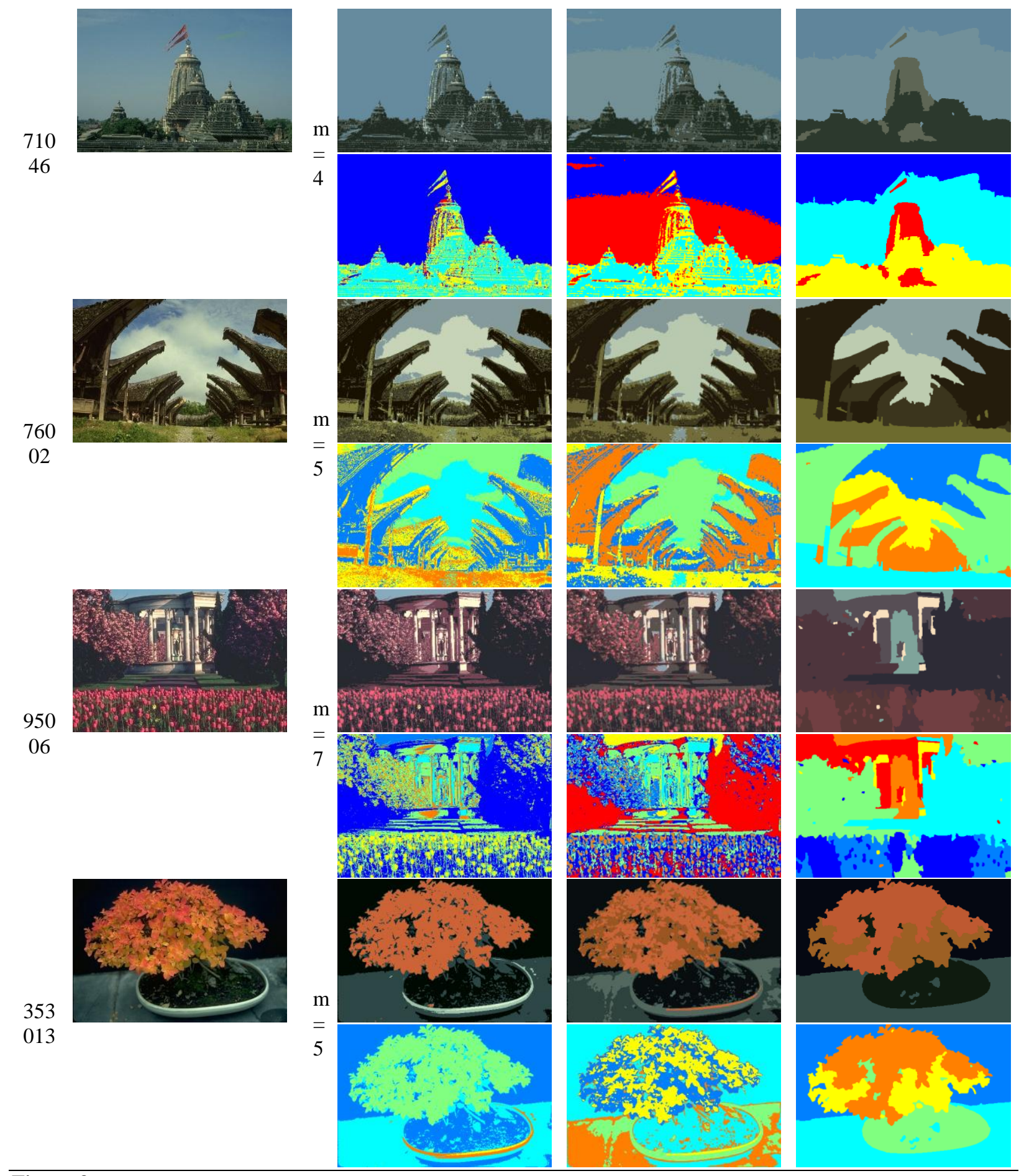

Figure 3. Continued

Table 2 shows that 3DHP required almost the same execution time for all images, while FCM took much longer to process large images such as '12003', '140075' and '189003'. With the exception of the images with four or less clusters, among all test images, the computational time of 3DHP is lower than FCM. However, the computational time of SFFCM for all images is lower than both 3DHP and FCM. The values achieved for the three evaluation functions 
$\mathrm{F}(\mathrm{I}), \mathrm{F}^{\prime}(\mathrm{I})$, and $\mathrm{Q}(\mathrm{I})$ suggest that all three methods yield consistent quantitative performance on the same image. However, the difference in these values is not substantial and in all cases they approach zero. The segmentation regions produced by the 3DHP method are more homogenous when inspected visually. The FCM method shows effective performance by producing good values for the three statistical measures $F(I), F^{\prime}(I)$, and Q(I). In most cases 3DHP provides better performance than SFFCM respect to F(I), F'(I), and Q(I). The success of FCM and SFFCM on certain images is a result of an appropriate number of clusters being chosen by the 3DHP method.

Table 3 shows that the results obtained by all methods are competitive for at least some images, as they outperformed each other in many cases. Due to a large number of test images in the Berkeley dataset, providing tables for all PRI, VoI and GCE values is impractical. Hence the average of whole dataset results has been presented in Table 4.

Table 1. Cluster centroids and peaks

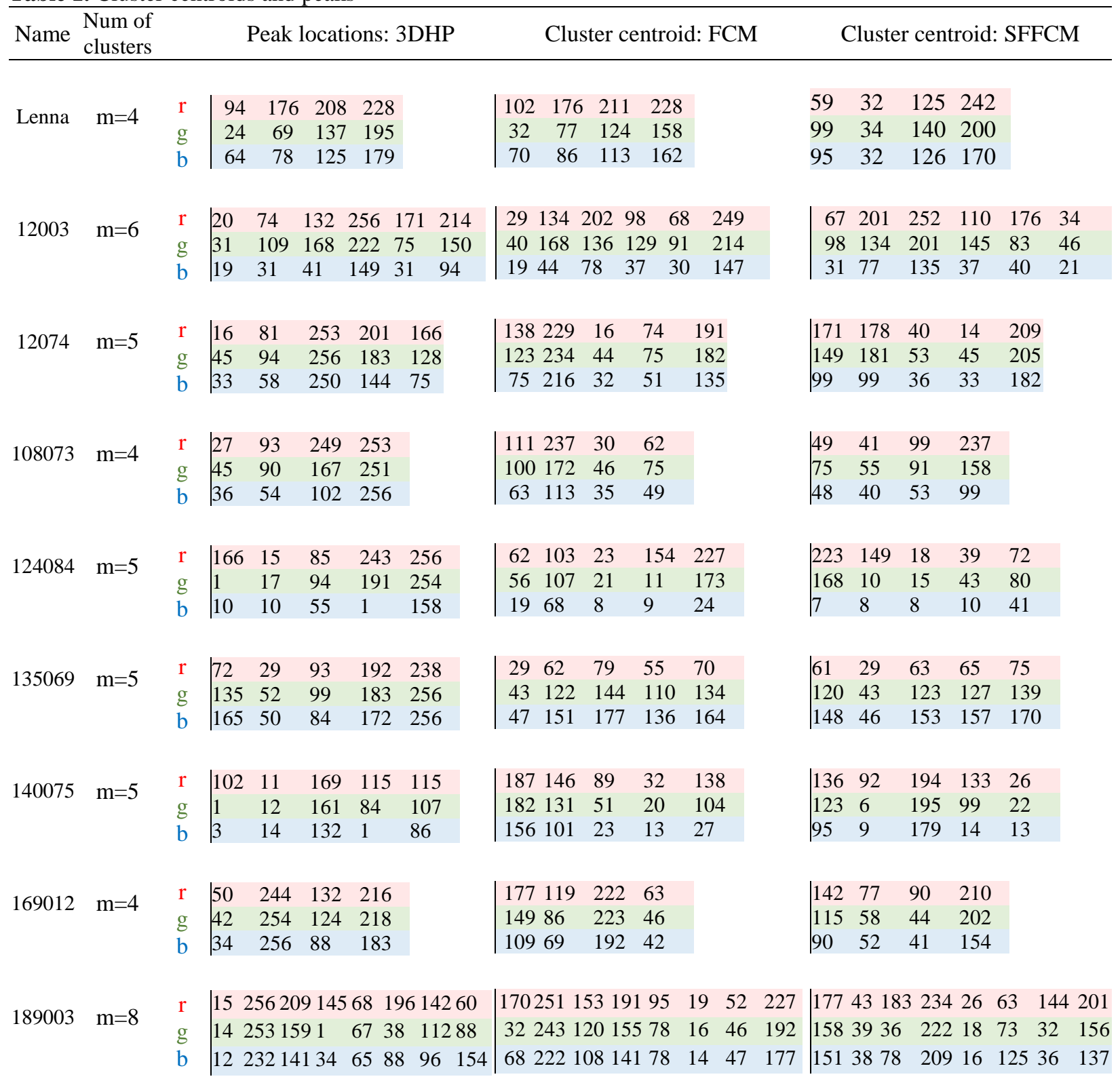




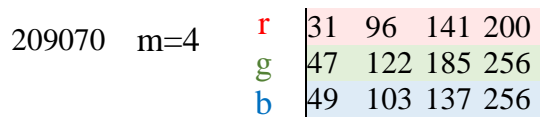

$$
\begin{aligned}
& \begin{array}{llll}
165 & 128 & 91 \quad 45
\end{array} \\
& 22016811963 \\
& \text { 181 } 13110163 \\
& \begin{array}{lll|llllll}
232038 \quad \mathrm{~m}=6 & \mathrm{r} & 19 & 110 & 65 & 122 & 179 & 243 \\
& & \mathrm{~g} & 29 & 147 & 98 & 121 & 160 & 221 \\
& & \mathrm{~b} & 15 & 215 & 38 & 111 & 162 & 214
\end{array} \\
& \begin{array}{llllll}
177 & 120 & 46 & 114 & 20 & 63
\end{array} \\
& \begin{array}{llllll}
165 & 156 & 62 & 119 & 32 & 92
\end{array} \\
& \begin{array}{llllll}
171 & 220 & 34 & 110 & 15 & 36
\end{array} \\
& \begin{array}{llllll}
60 & 48 & 119 & 178 & 118 & 18
\end{array} \\
& \begin{array}{llllll}
90 & 61 & 156 & 162 & 119 & 29
\end{array} \\
& \begin{array}{lllllll}
32 & 36 & 221 & 165 & 107 & 14
\end{array} \\
& \begin{array}{lll|lll}
238011 \quad \mathrm{~m}=3 & \mathrm{r} & 62 & 8 & 244 \\
& \mathrm{~g} & 80 & 38 & 213 \\
\mathrm{~b} & 137 & 36 & 218
\end{array} \\
& \begin{array}{lll}
54 & 9 & 62
\end{array} \\
& \begin{array}{lll}
70 & 37 & 79
\end{array} \\
& 12139 \quad 136 \\
& \begin{array}{lll}
63 & 59 & 7
\end{array} \\
& \begin{array}{lll}
80 & 76 & 37
\end{array} \\
& 13813134 \\
& \begin{array}{lll|llll}
35008 \mathrm{~m}=4 & \mathrm{r} & 20 & 84 & 156 & 216 \\
& \mathrm{~g} & 23 & 81 & 160 & 220 \\
& \mathrm{~b} & 14 & 53 & 158 & 205
\end{array} \\
& \mid \begin{array}{llll}
94 & 30 & 67 & 188 \\
117 & 40 & 75 & 195 \\
72 & 17 & 40 & 181
\end{array} \\
& \begin{array}{|llll}
54 & 70 & 64 & 145
\end{array} \\
& \begin{array}{llll}
70 & 113 & 65 & 150
\end{array} \\
& \begin{array}{llll}
30 & 45 & 38 & 144
\end{array}
\end{aligned}
$$

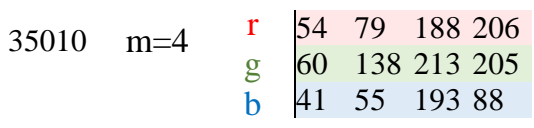

$$
\begin{aligned}
& \begin{array}{llll}
46 & 199 & 83 & 193
\end{array} \\
& \begin{array}{llll}
63 & 198 & 123 & 216
\end{array} \\
& \begin{array}{llll}
41 & 92 & 61 & 190
\end{array}
\end{aligned}
$$

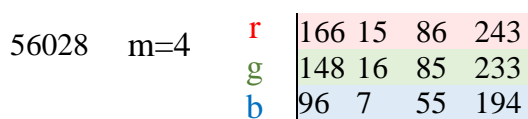

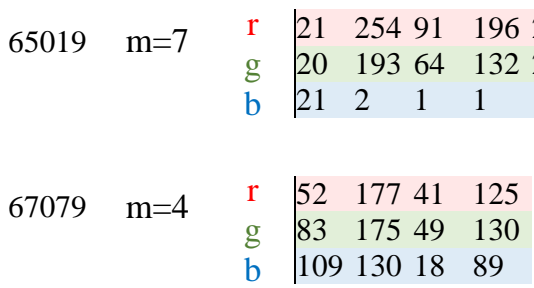

Table 1. Continued.

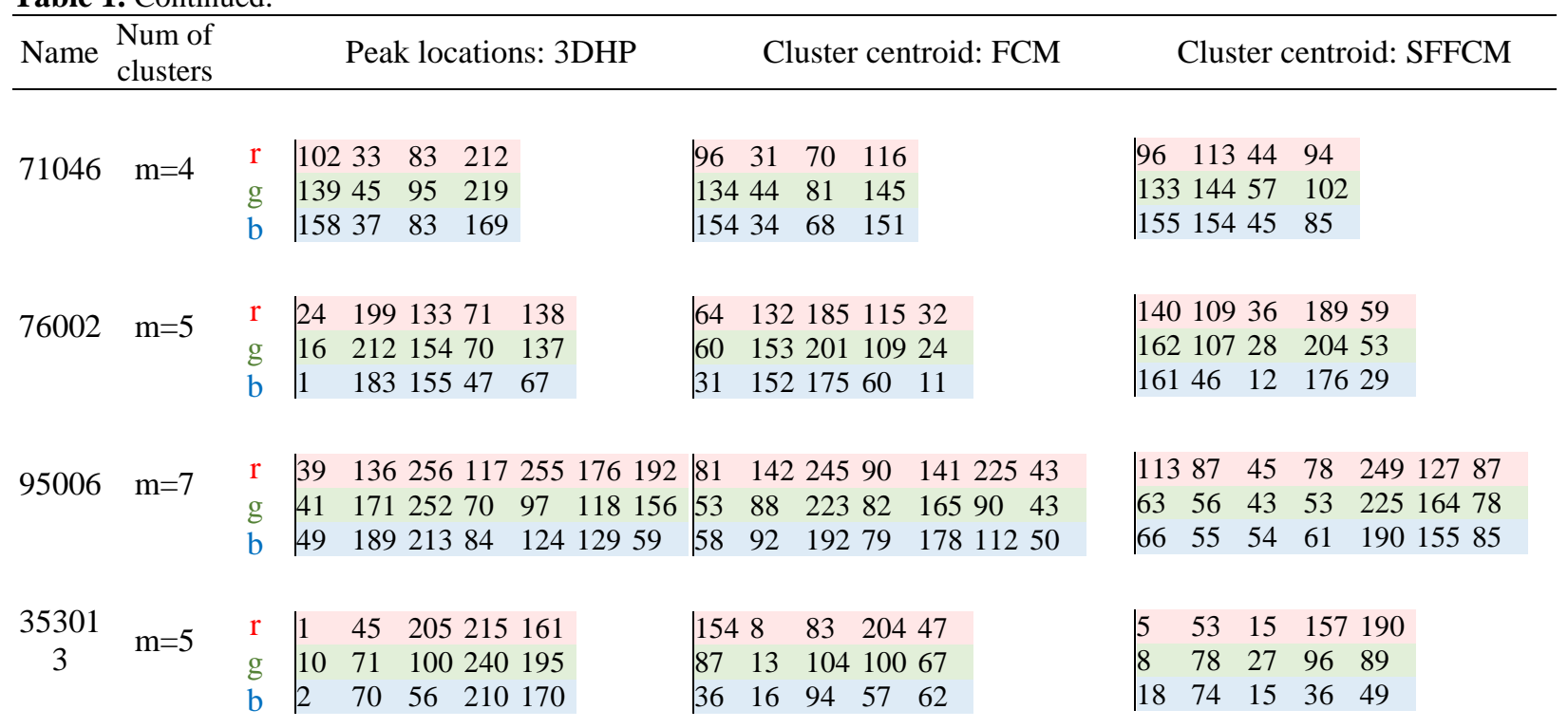


Table 2. Quantitative evaluation of results (F, F', Q and T).

\begin{tabular}{|c|c|c|c|}
\hline Name & $\begin{array}{c}\text { Quantitative evaluation } \\
\text { 3DHP }\end{array}$ & $\begin{array}{c}\text { Quantitative evaluation } \\
\text { FCM }\end{array}$ & $\begin{array}{c}\text { Quantitative evaluation } \\
\text { SFFCM }\end{array}$ \\
\hline $\begin{array}{c}\text { Len } \\
\text { na--na-- }\end{array}$ & $\begin{array}{l}F=1.3700 \mathrm{e}-06 \\
F^{\prime}=1.4000 \mathrm{e}-07 \\
Q=2.6600 \mathrm{e}-06 \\
T=6.0102\end{array}$ & $\begin{array}{l}F=1.2400 \mathrm{e}-06 \\
F^{\prime}=1.2000 \mathrm{e}-07 \\
Q=2.3800 \mathrm{e}-06 \\
T=1.2037\end{array}$ & $\begin{array}{l}\mathrm{F}=2.8797 \mathrm{e}-06 \\
\mathrm{~F}=2.8797 \mathrm{e}-07 \\
\mathrm{~F}=5.5049 \mathrm{e}-06 \\
\mathrm{~T}=1.0731\end{array}$ \\
\hline $\begin{array}{c}120 \\
03\end{array}$ & $\begin{array}{l}F=5.7133 e-07 \\
F^{\prime}=5.7133 e-08 \\
Q=0.00000159 \\
T=6.0912\end{array}$ & $\begin{array}{l}F=2.234 \mathrm{e}-07 \\
F^{\prime}=2.234 \mathrm{e}-08 \\
Q=6.1514 \mathrm{e}-07 \\
T=10.8642\end{array}$ & $\begin{array}{l}F=2.1131 \mathrm{e}-06 \\
F^{\prime}=2.1131 \mathrm{e}-07 \\
Q=5.1966 \mathrm{e}-06 \\
T=2.0153\end{array}$ \\
\hline $\begin{array}{c}120 \\
74\end{array}$ & $\begin{array}{l}\mathrm{F}=6.8033 \mathrm{e}-07 \\
\mathrm{~F}^{\prime}=6.8033 \mathrm{e}-08 \\
\mathrm{Q}=1.477 \mathrm{e}-06 \\
\mathrm{~T}=6.2889\end{array}$ & $\begin{array}{l}F=4.1665 \mathrm{e}-07 \\
F^{\prime}=4.1665 \mathrm{e}-08 \\
Q=9.3783 \mathrm{e}-07 \\
T=6.2983\end{array}$ & $\begin{array}{l}F=3.9226 \mathrm{e}-06 \\
F^{\prime}=3.9226 \mathrm{e}-07 \\
Q=8.0792 \mathrm{e}-06 \\
T=1.9179\end{array}$ \\
\hline $\begin{array}{l}108 \\
073\end{array}$ & $\begin{array}{l}F=1.2326 \mathrm{e}-06 \\
F^{\prime}=1.2326 \mathrm{e}-07 \\
Q=1.56 \mathrm{e}-06 \\
T=6.1383\end{array}$ & $\begin{array}{l}\mathrm{F}=2.5369 \mathrm{e}-07 \\
\mathrm{~F}^{\prime}=2.5369 \mathrm{e}-08 \\
\mathrm{Q}=6.245 \mathrm{e}-07 \\
\mathrm{~T}=3.2681\end{array}$ & $\begin{array}{l}\mathrm{F}=8.5821 \mathrm{e}-07 \\
\mathrm{~F}^{\prime}=8.5821 \mathrm{e}-08 \\
\mathrm{Q}=2.203 \mathrm{e}-06 \\
\mathrm{~T}=1.9291\end{array}$ \\
\hline $\begin{array}{l}124 \\
084\end{array}$ & $\begin{array}{l}F=1.8806 \mathrm{e}-06 \\
F^{\prime}=1.8806 \mathrm{e}-07 \\
Q=2.9142 \mathrm{e}-06 \\
T=5.8947\end{array}$ & $\begin{array}{l}F=6.1935 \mathrm{e}-07 \\
F^{\prime}=6.1935 \mathrm{e}-08 \\
Q=1.4125 \mathrm{e}-06 \\
T=6.1178\end{array}$ & $\begin{array}{l}\mathrm{F}=1.4316 \mathrm{e}-06 \\
\mathrm{~F}^{\prime}=1.4316 \mathrm{e}-07 \\
Q=3.5087 \mathrm{e}-06 \\
\mathrm{~T}=1.9511\end{array}$ \\
\hline $\begin{array}{l}135 \\
069\end{array}$ & $\begin{array}{l}F=5.2978 \mathrm{e}-06 \\
F^{\prime}=5.2978 \mathrm{e}-07 \\
Q=2.2316 \mathrm{e}-06 \\
T=6.3629\end{array}$ & $\begin{array}{l}\mathrm{F}=1.4337 \mathrm{e}-08 \\
F^{\prime}=1.4337 \mathrm{e}-09 \\
Q=3.3285 \mathrm{e}-08 \\
T=7.2662\end{array}$ & $\begin{array}{l}F=1.3683 \mathrm{e}-07 \\
F^{\prime}=1.3683 \mathrm{e}-08 \\
Q=3.1574 \mathrm{e}-07 \\
T=2.4723\end{array}$ \\
\hline $\begin{array}{l}140 \\
075\end{array}$ & $\begin{array}{l}F=4.6692 \mathrm{e}-07 \\
F^{\prime}=4.6692 \mathrm{e}-08 \\
Q=1.4902 \mathrm{e}-06 \\
T=6.5012\end{array}$ & $\begin{array}{l}\mathrm{F}=3.6162 \mathrm{e}-07 \\
F^{\prime}=3.6162 \mathrm{e}-08 \\
Q=1.1465 \mathrm{e}-06 \\
T=10.2341\end{array}$ & $\begin{array}{l}\mathrm{F}=8.0344 \mathrm{e}-07 \\
\mathrm{~F}^{\prime}=8.0344 \mathrm{e}-08 \\
\mathrm{Q}=2.4868 \mathrm{e}-06 \\
\mathrm{~T}=2.4577\end{array}$ \\
\hline $\begin{array}{l}169 \\
012\end{array}$ & $\begin{array}{l}\mathrm{F}=4.6059 \mathrm{e}-07 \\
\mathrm{~F}^{\prime}=4.6059 \mathrm{e}-08 \\
\mathrm{Q}=1.4619 \mathrm{e}-06 \\
\mathrm{~T}=6.1061\end{array}$ & $\begin{array}{l}\mathrm{F}=3.9575 \mathrm{e}-07 \\
\mathrm{~F}^{\prime}=3.9575 \mathrm{e}-08 \\
\mathrm{Q}=1.2622 \mathrm{e}-06 \\
\mathrm{~T}=5.9679\end{array}$ & $\begin{array}{l}\mathrm{F}=1.3975 \mathrm{e}-06 \\
F^{\prime}=1.3975 \mathrm{e}-07 \\
Q=4.6398 \mathrm{e}-06 \\
T=2.6330\end{array}$ \\
\hline $\begin{array}{l}189 \\
003\end{array}$ & $\begin{array}{l}F=1.2906 \mathrm{e}-06 \\
F^{\prime}=1.2906 \mathrm{e}-07 \\
Q=2.7658 \mathrm{e}-06 \\
T=6.2119\end{array}$ & $\begin{array}{l}\mathrm{F}=7.4229 \mathrm{e}-07 \\
\mathrm{~F}^{\prime}=7.4229 \mathrm{e}-08 \\
\mathrm{Q}=1.8435 \mathrm{e}-06 \\
\mathrm{~T}=14.7445\end{array}$ & $\begin{array}{l}\mathrm{F}=4.9384 \mathrm{e}-06 \\
\mathrm{~F}^{\prime}=4.9384 \mathrm{e}-07 \\
\mathrm{Q}=1.132 \mathrm{e}-05 \\
\mathrm{~T}=2.3438\end{array}$ \\
\hline $\begin{array}{l}209 \\
070\end{array}$ & $\begin{array}{l}F=5.4227 \mathrm{e}-07 \\
F^{\prime}=5.4227 \mathrm{e}-08 \\
Q=1.1735 \mathrm{e}-06 \\
T=6.2352\end{array}$ & $\begin{array}{l}\mathrm{F}=2.4162 \mathrm{e}-07 \\
F^{\prime}=2.4162 \mathrm{e}-08 \\
Q=7.1333 \mathrm{e}-07 \\
T=6.6647\end{array}$ & $\begin{array}{l}\mathrm{F}=8.6215 \mathrm{e}-07 \\
F^{\prime}=8.6215 \mathrm{e}-08 \\
Q=3 \mathrm{e}-06 \\
T=2.1026\end{array}$ \\
\hline $\begin{array}{c}2320 \\
38\end{array}$ & $\begin{array}{l}F=9.4895 \mathrm{e}-07 \\
F^{\prime}=9.4895 \mathrm{e}-08 \\
Q=1.2228 \mathrm{e}-06 \\
T=6.2871\end{array}$ & $\begin{array}{l}\mathrm{F}=2.1004 \mathrm{e}-07 \\
\mathrm{~F}^{\prime}=2.1004 \mathrm{e}-08 \\
\mathrm{Q}=5.1624 \mathrm{e}-07 \\
\mathrm{~T}=4.7355\end{array}$ & $\begin{array}{l}\mathrm{F}=5.6393 \mathrm{e}-07 \\
\mathrm{~F}^{\prime}=5.6393 \mathrm{e}-08 \\
\mathrm{Q}=1.4172 \mathrm{e}-06 \\
\mathrm{~T}=2.0963\end{array}$ \\
\hline $\begin{array}{l}238 \\
011\end{array}$ & $\begin{array}{l}F=1.457 \mathrm{e}-06 \\
F^{\prime}=1.457 \mathrm{e}-07 \\
Q=9.0549 \mathrm{e}-07 \\
T=6.0678\end{array}$ & $\begin{array}{l}\mathrm{F}=1.4087 \mathrm{e}-08 \\
\mathrm{~F}^{\prime}=1.4087 \mathrm{e}-09 \\
\mathrm{Q}=4.6698 \mathrm{e}-08 \\
\mathrm{~T}=2.9922\end{array}$ & $\begin{array}{l}\mathrm{F}=2.059 \mathrm{e}-08 \\
\mathrm{~F}^{\prime}=2.059 \mathrm{e}-09 \\
\mathrm{Q}=8.14 \mathrm{e}-08 \\
\mathrm{~T}=1.9768\end{array}$ \\
\hline
\end{tabular}

Table 2. Continued 


\begin{tabular}{|c|c|c|c|}
\hline $\begin{array}{c}350 \\
08\end{array}$ & $\begin{array}{l}F=4.1193 \mathrm{e}-07 \\
F^{\prime}=4.1193 \mathrm{e}-08 \\
Q=1.0089 \mathrm{e}-06 \\
T=6.4512\end{array}$ & $\begin{array}{l}F=2.8003 \mathrm{e}-07 \\
F^{\prime}=2.8003 \mathrm{e}-08 \\
Q=7.4904 \mathrm{e}-07 \\
T=4.0833\end{array}$ & $\begin{array}{l}F=6.7645 \mathrm{e}-07 \\
F^{\prime}=6.7645 \mathrm{e}-08 \\
Q=2.0802 \mathrm{e}-06 \\
T=1.9318\end{array}$ \\
\hline$\frac{350}{10}$ & $\begin{array}{l}F=2.4355 \mathrm{e}-07 \\
F^{\prime}=2.4355 \mathrm{e}-08 \\
Q=8.2145 \mathrm{e}-07 \\
T=6.3137\end{array}$ & $\begin{array}{l}F=1.0827 \mathrm{e}-07 \\
F^{\prime}=1.0827 \mathrm{e}-08 \\
Q=3.643 \mathrm{e}-07 \\
T=4.0775\end{array}$ & $\begin{array}{l}F=4.6721 \mathrm{e}-07 \\
F^{\prime}=4.6721 \mathrm{e}-08 \\
Q=1.6177 \mathrm{e}-06 \\
T=2.3095\end{array}$ \\
\hline $\begin{array}{c}560 \\
28\end{array}$ & $\begin{array}{l}\mathrm{F}=3.5229 \mathrm{e}-07 \\
\mathrm{~F}=3.5229 \mathrm{e}-08 \\
\mathrm{Q}=1.0031 \mathrm{e}-06 \\
\mathrm{~T}=6.2556\end{array}$ & $\begin{array}{l}F=2.3402 \mathrm{e}-07 \\
F^{\prime}=2.3402 \mathrm{e}-08 \\
Q=6.7532 \mathrm{e}-07 \\
T=5.6569\end{array}$ & $\begin{array}{l}F=7.001 \mathrm{e}-07 \\
F^{\prime}=7.001 \mathrm{e}-08 \\
Q=2.4089 \mathrm{e}-06 \\
T=2.0573\end{array}$ \\
\hline $\begin{array}{c}650 \\
19\end{array}$ & $\begin{array}{l}F=2.0482 \mathrm{e}-06 \\
F=2.0482 \mathrm{e}-07 \\
Q=3.3029 \mathrm{e}-06 \\
T=6.1657\end{array}$ & $\begin{array}{l}F=8.2575 \mathrm{e}-07 \\
F^{\prime}=8.2575 \mathrm{e}-08 \\
Q=2.0284 \mathrm{e}-06 \\
T=13.7039\end{array}$ & $\begin{array}{l}F=3.3699 \mathrm{e}-06 \\
F^{\prime}=3.3699 \mathrm{e}-07 \\
Q=8.0541 \mathrm{e}-06 \\
T=2.5992\end{array}$ \\
\hline $\begin{array}{c}670 \\
79\end{array}$ & $\begin{array}{l}F=1.4427 \mathrm{e}-07 \\
F=1.4427 \mathrm{e}-08 \\
Q=4.6106 \mathrm{e}-07 \\
\mathrm{~T}=6.2369\end{array}$ & $\begin{array}{l}F=5.7994 \mathrm{e}-08 \\
F^{\prime}=5.7994 \mathrm{e}-09 \\
Q=1.8602 \mathrm{e}-07 \\
T=4.0155\end{array}$ & $\begin{array}{l}F=3.4167 \mathrm{e}-07 \\
F^{\prime}=3.4167 \mathrm{e}-08 \\
Q=8.7742 \mathrm{e}-07 \\
T=1.9546\end{array}$ \\
\hline $\begin{array}{c}710 \\
46\end{array}$ & $\begin{array}{l}F=9.764 \mathrm{e}-07 \\
F=9.764 \mathrm{e}-08 \\
Q=9.7541 \mathrm{e}-07 \\
T=6.2244\end{array}$ & $\begin{array}{l}F=5.975 \mathrm{e}-08 \\
F^{\prime}=5.975 \mathrm{e}-09 \\
Q=1.8072 \mathrm{e}-07 \\
T=4.0063\end{array}$ & $\begin{array}{l}F=5.0245 \mathrm{e}-07 \\
F^{\prime}=5.0245 \mathrm{e}-08 \\
Q=1.2051 \mathrm{e}-06 \\
T=2.1358\end{array}$ \\
\hline $\begin{array}{c}760 \\
02\end{array}$ & $\begin{array}{l}\mathrm{F}=3.2006 \mathrm{e}-07 \\
\mathrm{~F}=3.2006 \mathrm{e}-08 \\
\mathrm{Q}=9.3846 \mathrm{e}-07 \\
\mathrm{~T}=6.1982\end{array}$ & $\begin{array}{l}F=2.1645 \mathrm{e}-07 \\
F^{\prime}=2.1645 \mathrm{e}-08 \\
Q=6.4376 \mathrm{e}-07 \\
T=6.4097\end{array}$ & $\begin{array}{l}\mathrm{F}=6.8293 \mathrm{e}-07 \\
F^{\prime}=6.8293 \mathrm{e}-08 \\
Q=2.0449 \mathrm{e}-06 \\
\mathrm{~T}=1.9069\end{array}$ \\
\hline $\begin{array}{c}950 \\
06\end{array}$ & $\begin{array}{l}F=7.8068 \mathrm{e}-06 \\
F=7.8068 \mathrm{e}-07 \\
Q=4.0658 \mathrm{e}-06 \\
T=6.3001\end{array}$ & $\begin{array}{l}F=9.6367 \mathrm{e}-07 \\
F^{\prime}=9.6367 \mathrm{e}-08 \\
Q=1.9532 \mathrm{e}-06 \\
T=11.3612\end{array}$ & $\begin{array}{l}F=4.0633 \mathrm{e}-06 \\
F^{\prime}=4.0633 \mathrm{e}-07 \\
Q=9.1928 \mathrm{e}-06 \\
T=2.5159\end{array}$ \\
\hline $\begin{array}{l}353 \\
013\end{array}$ & $\begin{array}{l}\mathrm{F}=1.1838 \mathrm{e}-06 \\
\mathrm{~F}=1.1838 \mathrm{e}-07 \\
\mathrm{Q}=1.9317 \mathrm{e}-06 \\
\mathrm{~T}=6.2308\end{array}$ & $\begin{array}{l}\mathrm{F}=2.2597 \mathrm{e}-07 \\
F^{\prime}=2.2597 \mathrm{e}-08 \\
Q=6.2344 \mathrm{e}-07 \\
T=10.1865\end{array}$ & $\begin{array}{l}\mathrm{F}=6.0339 \mathrm{e}-07 \\
F^{\prime}=6.0339 \mathrm{e}-08 \\
Q=1.8535 \mathrm{e}-06 \\
T=2.1671\end{array}$ \\
\hline
\end{tabular}

Table 3. Quantitative evaluation of results (PRI, VoI and GCE).

\begin{tabular}{|c|c|c|c|}
\hline Name & $\begin{array}{c}\text { Quantitative evaluation } \\
\text { 3DHP }\end{array}$ & $\begin{array}{c}\text { Quantitative evaluation } \\
\text { FCM }\end{array}$ & $\begin{array}{c}\text { Quantitative evaluation } \\
\text { SFFCM }\end{array}$ \\
\hline $\begin{array}{c}120 \\
03\end{array}$ & $\begin{array}{l}\mathrm{PRI}=0.702839 \\
\mathrm{VOI}=3.031937 \\
\mathrm{GCE}=0.392419\end{array}$ & $\begin{array}{l}\text { PRI }=0.699288 \\
\text { VOI }=3.365230 \\
\text { GCE }=0.432079\end{array}$ & $\begin{array}{l}\text { PRI }=0.706441 \\
\text { VOI }=2.409350 \\
\text { GCE }=0.308196\end{array}$ \\
\hline $\begin{array}{c}120 \\
74\end{array}$ & $\begin{array}{l}\mathrm{PRI}=0.646981 \\
\mathrm{VOI}=2.431389 \\
\mathrm{GCE}=0.371896\end{array}$ & $\begin{array}{l}\mathrm{PRI}=0.657461 \\
\mathrm{VOI}=2.475026 \\
\mathrm{GCE}=0.381657\end{array}$ & $\begin{array}{l}\mathrm{PRI}=0.756473 \\
\mathrm{VOI}=1.574813 \\
\mathrm{GCE}=0.196605\end{array}$ \\
\hline $\begin{array}{l}108 \\
073\end{array}$ & $\begin{array}{l}\mathrm{PRI}=0.591311 \\
\mathrm{VOI}=2.212177 \\
\mathrm{GCE}=0.301846\end{array}$ & $\begin{array}{l}\mathrm{PRI}=0.575904 \\
\mathrm{VOI}=2.552988 \\
\mathrm{GCE}=0.318638\end{array}$ & $\begin{array}{l}\mathrm{PRI}=0.594306 \\
\mathrm{VOI}=2.265117 \\
\mathrm{GCE}=0.291351\end{array}$ \\
\hline $\begin{array}{l}124 \\
084\end{array}$ & $\begin{array}{l}\mathrm{PRI}=0.715632 \\
\mathrm{VOI}=2.458209 \\
\mathrm{GCE}=0.337242\end{array}$ & $\begin{array}{l}\mathrm{PRI}=0.705431 \\
\mathrm{VOI}=2.718757 \\
\mathrm{GCE}=0.370913\end{array}$ & $\begin{array}{l}\mathrm{PRI}=0.719107 \\
\mathrm{VOI}=2.163888 \\
\mathrm{GCE}=0.272354\end{array}$ \\
\hline
\end{tabular}




\begin{tabular}{|c|c|c|c|}
\hline $\begin{array}{l}135 \\
069\end{array}$ & $\begin{array}{l}\mathrm{PRI}=0.985861 \\
\mathrm{VOI}=0.147977 \\
\mathrm{GCE}=0.016432\end{array}$ & $\begin{array}{l}\mathrm{PRI}=0.335102 \\
\mathrm{VOI}=1.994055 \\
\mathrm{GCE}=0.025972\end{array}$ & $\begin{array}{l}\mathrm{PRI}=0.396392 \\
\mathrm{VOI}=1.720451 \\
\mathrm{GCE}=0.025217\end{array}$ \\
\hline $\begin{array}{l}140 \\
-075\end{array}$ & $\begin{array}{l}\mathrm{PRI}=0.749074 \\
\mathrm{VOI}=3.508455 \\
\mathrm{GCE}=0.498595\end{array}$ & $\begin{array}{l}\mathrm{PRI}=0.737769 \\
\mathrm{VOI}=3.716510 \\
\mathrm{GCE}=0.539043\end{array}$ & $\begin{array}{l}\mathrm{PRI}=0.836686 \\
\mathrm{VOI}=2.073448 \\
\mathrm{GCE}=0.216793\end{array}$ \\
\hline $\begin{array}{l}169 \\
012\end{array}$ & $\begin{array}{l}\mathrm{PRI}=0.626588 \\
\mathrm{VOI}=4.269046 \\
\mathrm{GCE}=0.501943\end{array}$ & $\begin{array}{l}\mathrm{PRI}=0.674412 \\
\mathrm{VOI}=4.418008 \\
\mathrm{GCE}=0.556223\end{array}$ & $\begin{array}{l}\mathrm{PRI}=0.700653 \\
\mathrm{VOI}=3.275286 \\
\mathrm{GCE}=0.334645\end{array}$ \\
\hline $\begin{array}{l}189 \\
003\end{array}$ & $\begin{array}{l}\mathrm{PRI}=0.669132 \\
\mathrm{VOI}=4.147374 \\
\mathrm{GCE}=0.574200\end{array}$ & $\begin{array}{l}\mathrm{PRI}=0.683224 \\
\mathrm{VOI}=4.443397 \\
\mathrm{GCE}=0.607502\end{array}$ & $\begin{array}{l}\mathrm{PRI}=0.689975 \\
\mathrm{VOI}=3.404865 \\
\mathrm{GCE}=0.470955\end{array}$ \\
\hline $\begin{array}{l}209 \\
070\end{array}$ & $\begin{array}{l}\mathrm{PRI}=0.635576 \\
\mathrm{VOI}=4.409536 \\
\mathrm{GCE}=0.501888\end{array}$ & $\begin{array}{l}\mathrm{PRI}=0.663834 \\
\mathrm{VOI}=4.569162 \\
\mathrm{GCE}=0.539298\end{array}$ & $\begin{array}{l}\mathrm{PRI}=0.696154 \\
\mathrm{VOI}=3.573111 \\
\mathrm{GCE}=0.360163\end{array}$ \\
\hline $\begin{array}{c}2320 \\
38\end{array}$ & $\begin{array}{l}\mathrm{PRI}=0.838627 \\
\mathrm{VOI}=2.528876 \\
\mathrm{GCE}=0.300290\end{array}$ & $\begin{array}{l}\mathrm{PRI}=0.878349 \\
\mathrm{VOI}=2.503639 \\
\mathrm{GCE}=0.335550\end{array}$ & $\begin{array}{l}\mathrm{PRI}=0.899851 \\
\mathrm{VOI}=1.771766 \\
\mathrm{GCE}=0.217234\end{array}$ \\
\hline $\begin{array}{l}238 \\
011\end{array}$ & $\begin{array}{l}\mathrm{PRI}=0.930953 \\
\mathrm{VOI}=0.473332 \\
\mathrm{GCE}=0.055855\end{array}$ & $\begin{array}{l}\mathrm{PRI}=0.804132 \\
\mathrm{VOI}=0.957979 \\
\mathrm{GCE}=0.104131\end{array}$ & $\begin{array}{l}\mathrm{PRI}=0.669144 \\
\mathrm{VOI}=1.407235 \\
\mathrm{GCE}=0.145632\end{array}$ \\
\hline $\begin{array}{c}350 \\
08\end{array}$ & $\begin{array}{l}\mathrm{PRI}=0.600557 \\
\mathrm{VOI}=2.863001 \\
\mathrm{GCE}=0.260084\end{array}$ & $\begin{array}{l}\mathrm{PRI}=0.625892 \\
\mathrm{VOI}=3.237172 \\
\mathrm{GCE}=0.355314\end{array}$ & $\begin{array}{l}\mathrm{PRI}=0.658769 \\
\mathrm{VOI}=2.601046 \\
\mathrm{GCE}=0.222847\end{array}$ \\
\hline $\begin{array}{c}350 \\
10\end{array}$ & $\begin{array}{l}\mathrm{PRI}=0.728838 \\
\mathrm{VOI}=3.515352 \\
\mathrm{GCE}=0.419921\end{array}$ & $\begin{array}{l}\mathrm{PRI}=0.733839 \\
\mathrm{VOI}=3.552653 \\
\mathrm{GCE}=0.432048\end{array}$ & $\begin{array}{l}\mathrm{PRI}=0.719058 \\
\mathrm{VOI}=3.148263 \\
\mathrm{GCE}=0.345505\end{array}$ \\
\hline $\begin{array}{c}560 \\
28\end{array}$ & $\begin{array}{l}\mathrm{PRI}=0.592725 \\
\mathrm{VOI}=3.714739 \\
\mathrm{GCE}=0.438474\end{array}$ & $\begin{array}{l}\mathrm{PRI}=0.603916 \\
\mathrm{VOI}=3.765604 \\
\mathrm{GCE}=0.442325\end{array}$ & $\begin{array}{l}\mathrm{PRI}=0.625383 \\
\mathrm{VOI}=3.040313 \\
\mathrm{GCE}=0.316286\end{array}$ \\
\hline $\begin{array}{c}650 \\
19\end{array}$ & $\begin{array}{l}\mathrm{PRI}=0.764709 \\
\mathrm{VOI}=4.731903 \\
\mathrm{GCE}=0.422061\end{array}$ & $\begin{array}{l}\mathrm{PRI}=0.838701 \\
\mathrm{VOI}=5.246779 \\
\mathrm{GCE}=0.581516\end{array}$ & $\begin{array}{l}\mathrm{PRI}=0.867411 \\
\mathrm{VOI}=3.410182 \\
\mathrm{GCE}=0.258204\end{array}$ \\
\hline $\begin{array}{c}670 \\
79\end{array}$ & $\begin{array}{l}\mathrm{PRI}=0.752014 \\
\mathrm{VOI}=2.840880 \\
\mathrm{GCE}=0.327411\end{array}$ & $\begin{array}{l}\mathrm{PRI}=0.750624 \\
\mathrm{VOI}=2.917691 \\
\mathrm{GCE}=0.342623\end{array}$ & $\begin{array}{l}\mathrm{PRI}=0.716400 \\
\mathrm{VOI}=2.143727 \\
\mathrm{GCE}=0.153132\end{array}$ \\
\hline $\begin{array}{c}710 \\
46\end{array}$ & $\begin{array}{l}\mathrm{PRI}=0.902722 \\
\mathrm{VOI}=1.547911 \\
\mathrm{GCE}=0.183469\end{array}$ & $\begin{array}{l}\mathrm{PRI}=0.708500 \\
\mathrm{VOI}=2.201056 \\
\mathrm{GCE}=0.297266\end{array}$ & $\begin{array}{l}\mathrm{PRI}=0.722012 \\
\mathrm{VOI}=1.825423 \\
\mathrm{GCE}=0.266854\end{array}$ \\
\hline $\begin{array}{c}760 \\
02\end{array}$ & $\begin{array}{l}\mathrm{PRI}=0.766120 \\
\mathrm{VOI}=3.483626 \\
\mathrm{GCE}=0.521048\end{array}$ & $\begin{array}{l}\mathrm{PRI}=0.779309 \\
\mathrm{VOI}=3.440196 \\
\mathrm{GCE}=0.513478\end{array}$ & $\begin{array}{l}\mathrm{PRI}=0.799879 \\
\mathrm{VOI}=2.458226 \\
\mathrm{GCE}=0.306349\end{array}$ \\
\hline $\begin{array}{c}950 \\
06\end{array}$ & $\begin{array}{l}\mathrm{PRI}=0.617331 \\
\mathrm{VOI}=3.350518 \\
\mathrm{GCE}=0.543149\end{array}$ & $\begin{array}{l}\text { PRI }=0.687417 \\
\text { VOI }=3.671150 \\
\text { GCE }=0.583522\end{array}$ & $\begin{array}{l}\mathrm{PRI}=0.770048 \\
\mathrm{VOI}=2.420249 \\
\mathrm{GCE}=0.359053\end{array}$ \\
\hline
\end{tabular}




\begin{tabular}{llll}
353 & $\mathrm{PRI}=0.751297$ & $\mathrm{PRI}=0.724700$ & $\mathrm{PRI}=0.825604$ \\
013 & $\mathrm{VOI}=2.025594$ & VOI $=2.350025$ & VOI $=1.402835$ \\
& $\mathrm{GCE}=0.286181$ & $\mathrm{GCE}=0.415924$ & GCE $=0.240564$ \\
\hline
\end{tabular}

\begin{tabular}{llll}
\hline \multicolumn{4}{l}{ Table 4. Mean values of PRI, VoI and GCE over the Berkeley dataset. } \\
\hline & PRI & VoI & GCE \\
3DHP & 0.685857 & 2.765545 & 0.360208 \\
FCM & 0.688451 & 2.979884 & 0.413387 \\
SFFCM & 0.739651 & 2.130512 & 0.258597 \\
\hline
\end{tabular}

Based on these results, we conclude that the 3DHP, FCM and SFFCM techniques can all show high quality performance in the segmentation process for at least some images. As it is clear from both visual and numerical results, the proposed 3DHP technique yields promising segmentation results. This is supported by the capability of the method to produce the number of clusters and cluster centroids automatically.

\section{Conclusion}

In this paper, we have introduced a new automated pixel clustering and color image segmentation algorithm. The proposed approach (3DHP) can automatically determine an appropriate number of clusters as well as the cluster centroids, demonstrating the advantage of peak detection using a multimodal optimization algorithm. Since the best number of clusters is often not known a priori in many practical applications, 3DHP can be utilized more widely in practice than existing approaches. The majority of images with differing numbers of clusters from a well-known benchmark data set have been demonstrated to be handled effectively by the proposed approach. The computational experiments have illustrated that the proposed algorithm can automatically discover all known cluster centroids. More importantly, the time required for clustering is not dependent on the size of the image to be segmented. Our approach uses relatively less time to find the cluster centroids compared to FCM, making it a viable algorithm for image segmentation. Furthermore, both the proposed method and FCM and SFFCM yield desirable results in terms of the quantitative evaluation function. The difference in these values is not significant and, for all three techniques, these values approach zero. Finally, experimental results confirm that the proposed 3DHP method can obtain robust and promising segmentation results.

\section{References}

Aziz, M. A. E., Ewees, A. A., \& Hassanien, A. E. (2017). Whale Optimization Algorithm and Moth-Flame Optimization for multilevel thresholding image segmentation. Expert Systems with Applications, 83, 242-256.

Barrera, J., \& Coello Coello, C. A. (2009). A Particle Swarm Optimization Method for Multimodal Optimization Based on Electrostatic Interaction. In A. H. Aguirre, R. M. Borja \& C. A. R. Garciá (Eds.), MICAI 2009: Advances in Artificial Intelligence: 8th Mexican International Conference on Artificial Intelligence, Guanajuato, México, November 9-13, 2009. Proceedings (pp. 622-632). Berlin, Heidelberg: Springer Berlin Heidelberg.

Borsotti, M., Campadelli, P., \& Schettini, R. (1998). Quantitative evaluation of color image segmentation results. Pattern recognition letters, 19, 741-747.

Brits, R., Engelbrecht, A. P., \& van den Bergh, F. (2007). Locating multiple optima using particle swarm optimization. Applied Mathematics and Computation, 189(2), 1859-1883.

Chang, D., Zhao, Y., Liu, L., \& Zheng, C. (2016). A dynamic niching clustering algorithm based on individual-connectedness and its application to color image segmentation. Pattern recognition, 60, 334-347. 
Chen, L., Papandreou, G., Kokkinos, I., Murphy, K., \& Yuille, A. L. (2018). DeepLab: Semantic Image Segmentation with Deep Convolutional Nets, Atrous Convolution, and Fully Connected CRFs. IEEE Transactions on Pattern Analysis and Machine Intelligence, 40, 834-848.

Cheng, H.-D., Jiang, X. H., Sun, Y., \& Wang, J. (2001). Color image segmentation: advances and prospects. Pattern recognition, 34, $2259-2281$.

Eberhart, R., \& Kennedy, J. (1995). A new optimizer using particle swarm theory. In Micro Machine and Human Science, 1995. MHS'95., Proceedings of the Sixth International Symposium on (pp. 39-43): IEEE.

He, L., \& Huang, S. (2017). Modified firefly algorithm based multilevel thresholding for color image segmentation. Neurocomputing, 240, 152174.

Hettiarachchi, R., \& Peters, J. F. (2017). Voronoï region-based adaptive unsupervised color image segmentation. Pattern recognition, 65, 119-135.

Horng, M.-H., \& Liou, R.-J. (2011). Multilevel minimum cross entropy threshold selection based on the firefly algorithm. Expert Systems with Applications, 38, 14805-14811.

Kapur, J., Sahoo, P. K., \& Wong, A. K. (1985). A new method for gray-level picture thresholding using the entropy of the histogram. Computer vision, graphics, and image processing, 29, 273-285.

Khairuzzaman, A. K. M., \& Chaudhury, S. (2017). Multilevel thresholding using grey wolf optimizer for image segmentation. Expert Systems with Applications, 86, 64-76.

Kumar, S., Pant, M., Kumar, M., \& Dutt, A. (2015). Colour image segmentation with histogram and homogeneity histogram difference using evolutionary algorithms. International Journal of Machine Learning and Cybernetics, 1-21.

Kurugollu, F., Sankur, B., \& Harmanci, A. E. (2001). Color image segmentation using histogram multithresholding and fusion. Image and vision computing, 19, 915-928.

Lei, T., Jia, X., Zhang, Y., Liu, S., Meng, H., \& Nandi, A. K. (2018). Superpixel-based Fast Fuzzy C-Means Clustering for Color Image Segmentation. IEEE Transactions on Fuzzy Systems, 1-1.

Li, X. (2007). A multimodal particle swarm optimizer based on fitness Euclidean-distance ratio. In Proceedings of the 9th annual conference on Genetic and evolutionary computation (pp. 78-85): ACM.

Liu, J., \& Yang, Y.-H. (1994). Multiresolution color image segmentation. IEEE Transactions on Pattern Analysis and Machine Intelligence, 16, 689-700.

Martin, D., Fowlkes, C., Tal, D., \& Malik, J. (2001). A database of human segmented natural images and its application to evaluating segmentation algorithms and measuring ecological statistics. In Proceedings Eighth IEEE International Conference on Computer Vision. ICCV 2001 (Vol. 2, pp. 416-423 vol.412).

Meila, M. (2002). Comparing clusterings.

Navon, E., Miller, O., \& Averbuch, A. (2005). Color image segmentation based on adaptive local thresholds. Image and vision computing, 23, 6985.

Otsu, N. (1979). An automatic threshold selection method based on discriminate and least squares criteria. Denshi Tsushin Gakkai Ronbunshi, 63, 349-356.

Panagiotakis, C., Grinias, I., \& Tziritas, G. (2011). Natural Image Segmentation Based on Tree Equipartition, Bayesian Flooding and Region Merging. IEEE Transactions on Image Processing, 20, 2276-2287.

Pare, S., Kumar, A., Bajaj, V., \& Singh, G. K. (2016). A multilevel color image segmentation technique based on cuckoo search algorithm and energy curve. Applied Soft Computing, 47, 76-102.

Parsopoulos, K. E., \& Vrahatis, M. N. (2001). Modification of the particle swarm optimizer for locating all the global minima. In Artificial Neural Nets and Genetic Algorithms (pp. 324-327). Springer, Vienna.

Qu, B.-Y., Liang, J. J., \& Suganthan, P. N. (2012). Niching particle swarm optimization with local search for multi-modal optimization. Information Sciences, 197, 131-143.

Raja, N., Rajinikanth, V., \& Latha, K. (2014). Otsu based optimal multilevel image thresholding using firefly algorithm. Modelling and Simulation in Engineering, 2014, 37.

Rajinikanth, V., Aashiha, J., \& Atchaya, A. (2014). Gray-level histogram based multilevel threshold selection with bat algorithm. International Journal of Computer Applications, 93.

Rajinikanth, V., \& Couceiro, M. S. (2015). RGB Histogram Based Color Image Segmentation Using Firefly Algorithm. Procedia Computer Science, 46, 1449-1457.

Sarabi, A., \& Aggarwal, J. K. (1981). Segmentation of chromatic images. Pattern recognition, 13, 417-427.

Sarkar, S., \& Das, S. (2013). Multilevel image thresholding based on 2D histogram and maximum Tsallis entropy-a differential evolution approach. IEEE Transactions on Image Processing, 22, 4788-4797.

Sathya, P. D., \& Kayalvizhi, R. (2011). Optimal multilevel thresholding using bacterial foraging algorithm. Expert Systems with Applications, 38, 15549-15564.

Schacter, B. J., Davis, L. S., \& Rosenfeld, A. (1976). Scene segmentation by cluster detection in color spaces. ACM SIGART Bulletin, 16-17.

Shapiro, L. G., \& Stockman, G. C. Computer Vision, 2001, 279-325. In: New Jersey, Prentice-Hall, ISBN 0-13-030796-3.

Siang Tan, K., \& Mat Isa, N. A. (2011). Color image segmentation using histogram thresholding - Fuzzy C-means hybrid approach. Pattern recognition, 44, 1-15.

Sutton, M. A., Bezdek, J. C., \& Cahoon, T. C. (2000). Image segmentation by fuzzy clustering: methods and issues. In Handbook of medical imaging (pp. 87-106): Academic Press, Inc.

Syu, J., Wang, S., \& Wang, L. (2017). Hierarchical Image Segmentation Based on Iterative Contraction and Merging. IEEE Transactions on Image Processing, 26, 2246-2260.

Tenenbaum, J. M., Garvey, T. D., Weyl, S., \& Wolf, H. C. (1974). An Interactive Facility for Scene Analysis Research. In: STANFORD RESEARCH INST MENLO PARK CALIF.

Underwood, S., \& Aggarwal, J. (1977). Interactive computer analysis of aerial color infrared photographs. Computer Graphics and Image Processing, 6, 1-24.

Wang, H., Moon, I., Yang, S., \& Wang, D. (2012). A memetic particle swarm optimization algorithm for multimodal optimization problems. Information Sciences, 197, 38-52.

Yang, Y., \& Huang, S. (2012). Image segmentation by fuzzy C-means clustering algorithm with a novel penalty term. Computing and Informatics, 26, 17-31. 